\title{
Lethal and Sublethal Toxicity of Fipronil and Imidacloprid on Psyttalia concolor (Hymenoptera: Braconidae)
}

\author{
ÁNGELES ADÁN, ${ }^{2}$ ELISA VINUUELA, PALOMA BENGOCHEA, FLOR BUDIA, \\ PEDRO DEL ESTAL, PEDRO AGUADO, AND PILAR MEDINA
}

Unidad de Protección de Cultivos, E.T.S.I. Agrónomos, Universidad Politécnica de Madrid, 28040 Madrid, Spain

\section{J. Econ. Entomol. 104(5): 1541-1549 (2011); DOI: http://dx.doi.org/10.1603/EC11019}

\begin{abstract}
Psyttalia concolor (Szèpligeti) (Hymenoptera: Braconidae) is a koinobiont endoparasitoid of several species of tephritid (Diptera) larvae, such as Bactrocera oleae (Gmelin) and Ceratitis capitata (Wiedemann). Here, we report on the effects of imidacloptid and fipronil on $P$. concolor fernales, when different routes of exposure were evaluated: residual contact (cover and bait sprays) and via treatment of host species. Moreover, the persistence of the bait formulated compound also was studied. For each experiment, lethal (mortality) and sublethal effects (parasitization rate or longevity) were studied. Fipronil produced $100 \%$ mortality irrespective of exposure route, and it was very persistent, because 34 -d-old residues still produced this high mortality rate, being as toxic or even more toxic than the reference product dimethoate. Toxicity of imidacloprid depends on the mode of exposure, although always remained less toxic than dimethoate. Imidacloprid caused high mortality or sublethal effect to the progeny in cover sprays and when applied via treated host, being harmless in bait sprays application. In conclusion, our results suggest that fipronil should not be used in the field when the parasitoid is present. On the contrary, although imidacloprid is physiologically active against females of $P$. concolor, ecological selectivity may result through the use of bait treatment.
\end{abstract}

KWY WORDS Psyttalia concolor, fpronil, imidacloprid, side effects

In recent years, integrated pest management programs to control tephritid fruit tlies are being implemented. It can be mentioned as examples the control of Mediterranean fruit fly, Ceratitis capitata (Wiedemann), in Spain (Urbaneja et al. 2009), several fruit flies in $\mathrm{H}_{2}$ waii (Vargas et al. 2010), and olive fruit fly, Bactrocera oleae (Gmelin), in California (Sime et al. 2006). Biological control with braconid parasitoids is one of the most environmentally friendly control strategies, but the most efficient method at present remains chemical control, which is routinely used worldwide (Liaropoulos et al. 2005, Mazor 2009, Urbaneja et al, 2009). Consequently, natural enemies must coexist with pesticides, and it is necessary to combine selective insecticides with natural enemies conservation.

Psyttalia (Opius) concolor (Szèpligeti) (Hymenoptera: Braconidae) is a koinobiont endoparasitoid of several species of tephritid larvae, such as the olive fruit fly and the Mediterranean fruit $\mathrm{fl} y$. This parasitoid has been used in the south of Europe for biological control of the olive frutit fly through inundative and propagative releases, with variable results (Jiménez et al. 1990). At present, this parasitoid is being evaluated in California for use as a biological control agent of $B$. oleae (Sime et al, 2006, Wang et al. 2009).

\footnotetext{
1 Corresponding author, e-nail: angeles.adan@ypm.es.
}

The need for new insecticides for fruit fly control has increased recently because of several bans and restrictions on many organophosphate and carbarnate insecticides in many regions as the United States and Europe. Fipronil and imidacloprid are two modern neurotoxic insecticides considered to be less damag. ing to ecosystems than older neurotoxic products, such as organophosphates (Stark and Vargas 2005, 2009).

Fipronil (a phenyl pyrazole insecticide) is a potent blocker of the GABA-regulated chloride channels in the neurons of the central nervous system. When this function is blocked by fpronil, the result is neural excitation and the death of the insect (Cole et al 1993). Fipronil kills the insects by contact and ingestion. It is effective against larval and adult stages of both piercing-sucking and chewing insects and can be effectively delivered via soil, foliar, bait, or seed applications (Burris et al. 1994).

Imidacloprid is a chloronicotinyl insecticide that acts on the nicotinic acetylcholine receptors of the insect nervous system (Elbert et al. 1991). It has good systemic activity and is particularly effective against homopteran pests (Lowery and Smirle 2003).

Fipronil and imidacloprid have been tested for use in the chemical control of several tephritid species (Barry et al. 2004, Ruiz et al. 2004, Vargas et al. 2005, Yee and Alston 2006, Ruiz Torres and Montiel Bueno 
2007, Stark and Vargas 2009), and they have been registered for the control of fruit flies in several countries. For example, fipronil is being used in a bait spray for the contral of tephritid fruit flies in the South Pacific and Australia (Allwood et al. 2002, Stark and Vargas 2009), and imidacloprid is currently registered in Spain for use in olive, Olea europaea $\mathrm{L}_{\text {, }}$ groves against B olea (MARM 2011). However, to our knowledge, there is little information available regarding the toxicity of fipronil and imidacloprid on the braconid parasitoids of tephritid pests, including $P$. concolor.

Therefore, in this study, with the goal of increasing our knowledge on the side effects of these pesticides, we evaluated their lethal and sublethal effects on $P$. concolor females in laboratory and semifield assays by using cover sprays and localized bait sprays. The organophosphate dimethoate was used as reference product. This insecticide is commonly used in olive crops in Spain against olive fruit fly for cover and bait sprays. In addition, the route of exposure via treated host was assessed.

\section{Materials and Methods}

Insects. The wasps used in these tests came from a laboratory colony maintained in a controlled environment cabinet $\left(25 \pm 2^{\circ} \mathrm{C}, 75 \pm 5 \% \mathrm{RH}\right.$, and a photoperiod of 16:8 [L:D] $h$ ) and reared in the host $C$. capitata, following standard procedures (Jacas and Vinuela 1994). The colonies of $P$. concolor and $C$. capitata have been reared for more than thirty years in our laboratory, and renewed periodically with individuals obtained from field or other colonies.

Chemicals. Commercial formulations of Regente ( $80 \%$ fpronil, WG, Basf Española, Spain), Confidor (20\% imidacloprid, LS, Bayer Crop Science, Spain), and Sistematon (40\% dimethoate, EC, Agrodan, Spain) were tested.

For cover sprays, fresh solution in distilled water of every commercial product were prepared before the assays at the highest recommended concentration of the active ingredient (AI) for other crops, $150 \mathrm{mg}$ (AI) / liter imidacloprid and $40 \mathrm{mg}$ (AI)/liter fpronil, because they still not registered in Spain for olive crops at the time the experiments were carried out. As reference product, dimethoate was tested at the highest recommended concentration of the active ingredient, $600 \mathrm{mg}$ (AI)/liter, for cover sprays in olive crops according to Spanish registration (MARM 20l1). Controls were treated with water alone.

It is a common technique used against fruit flies in general, and B. oleae in particular, to applied some of the insecticides registered for its control mixed with a protein bait. As a consequence, for bait spray assays, Biocebo (proteins hydrolyzed at 30\% SL, Bioiberica, Spain) also was used as a different control (it contains any insecticide) and was added to the pesticides.

In this case, insecticides were prepared in distilled water by dilution of the corresponding amount of insecticide with the protein bait. Concentrations tested were as follows: $3,000+2,250 \mathrm{mg}$ (AI)/liter, according to Spanish registration for dimethoate balt sprays in olives; $150+2,250 \mathrm{mg}$ (AI)/liter and 40 \% $2,250 \mathrm{mg}$ (AI) /liter of imidacloprid + bait and fipro. nil + bait (insecticides used at the concentration cited here, and bait was prepared at the same con centration tested with dimethoate for a better con parisonk). The concentration $1,500+2,250 \mathrm{mg}$ (AI) liter imidacloprid + bait was chosen taking into account that it was the concentration tested at that moment in field assays for registration purposes (Ruiz et al. 2007). Bait at 4,500 $\mathrm{mg}$ ( $\mathrm{Ar}$ )/liter (maximum concentration recommended as attractant for fruit flies) also was evaluated to discard possible toxicity on $P$. concolor. The control only contained water.

Experimental Conditions. Unless otherwise stated, environmental conditions in experiments were 25 $2^{\circ} \mathrm{C}, 75 \pm 5 \% \mathrm{RH}$, and a photoperiod of $16: 8$ (L:D) $h$

Exposure via Residual Contact. All the residual ex periments were done with $<48$-h-old mated females. According to International Organization for Biological and Integrated Control of Noxious Animals and Plants (IOBC), adults are the most exposed life stage of the endoparasitoids (Hassan 1994). Male P. concolor have a shorter life span than females (Ragusa 1974). They copulate only once in life, just after the female emer gence. Females were chosen because sublethal or de layed effects could be studied by measuring reduction in parasitism (Jacas and Viñuela 1994). Young females. were chosen because older females may die within the testing period, thus making it more difficult to obtain reliable results from the assay. Water and food (a ground mixture of brewer's yeast and sugar [1:4, wt wt) were always offered ad libitum.

For each experiment, lethal (mortality) and sub lethal effects (parasitization rate or longevity in the case of cover spray, laboratory test) were studied Mortality was recorded at 24,48 , and $72 \mathrm{~h}$. Afterward, insects were always moved to different untreated cages to follow the evaluation.

The parasitization rate was scored as the percentage of attacked hosts and offspring per female, following the methodology described by Jacas and Vinuela (1994), with slight modifications. To test parasitiza tion, eight or 10 3-d-old-pesticide-exposed females were isolated in untreated plastic cages $(12 \mathrm{~cm}$ in diameter, $5 \mathrm{~cm}$ in height), whose floor had a round hole ( $5 \mathrm{~cm}$ in diameter) covered by a gauze. Distilled water was provided ad libitum in small glass vials ( 30 by $35 \mathrm{~mm}$ ) covered with Parafilm, and with a piece of Spontex wiper leaking out of it. Diet was supplied in small plastic stoppers ( $24 \mathrm{by} 6 \mathrm{~mm}$ ), both of them fixed to the floor with Plasticine. During the next $4 \mathrm{~d}, 20$ 7-d-old (mature third-instar) C. capitata larvae were offered daily to each female for parasitization for $2 \mathrm{~h}$. Larvae of the fruit fly were immobilized by sandwiching them between the mesh of the cage's floor and a piece of Parafilm. Parafilm was placed on the floor of a glass pot put upside down and all the structure (the cage and the glass pot) was hold together with a rubber band. After $2 \mathrm{~h}$ of exposure to parasitization, $C$. capitata larvae from each female and day were placed onto petri dishes to let them pupate. After $3 w k$, the 
number of emerging adults of $P$. concolor and $C$ capttata (nonparasitized host larvae) were recorded and compared with the number of offered host larvae. The percentage of attacked host (percentage of puparia without medfly emergence) and offspring (percentage of parasitoids emerged from parasitized puparia). The parasitization rate was evaluated only with insecticides that caused $<50 \%$ of mortality after $72 \mathrm{~h}$ of exposure.

Cover Spray (Laboratory Test). To evaluate the residual contact activity of pesticides, glass plates (12 by 12 by $0.5 \mathrm{~cm}$ thick) were treated with the chemicals under a Potter Precision Spray Tower (Burkard Manufacturing Co., Rickmansworth, Hertfordshire, United Kingdom) with an homogenous deposit of $1.79 \pm 0.13$ $\mathrm{ng} / \mathrm{cm}^{2}(1 \mathrm{ml} ; 55 \mathrm{kPa})$ which is within the interval recommended by the IOBC validity criteria for run* hing ecotoxicological experiments on beneficial arthropods (1.5-2 $\mathrm{mg} / \mathrm{cm}^{2}$ ) (Hassan 1994). As soon as the glass plates were dry ( $2 \mathrm{~h}$ after the treatment), 448-h-old mated females were exposed to the insecticides by using the test cages designed for $P$. concolor tests developed by Jacas and Viñuela (1994). Test units consisted of a round methacrylate frame $(10 \mathrm{~cm}$ in diameter, $3 \mathrm{~cm}$ in height) and the two square glass plates described above. The plastic frame had seven boles ( $1 \mathrm{~cm}$ in diameter): four holes were covered by a mesh for ventilation; one hole was used for insect manipulation and closed by a cork stopper; one hole was connected to a rubber bulb filled with drinking water and a piece of Spontex; and the last hole, holding an hypodermic needle connected to a rubber tube, provided a continuous flow of air produced by an aqzarium pump to ensure forced ventilation. The round frame and the plates were mounted with two rubber bands. Diet was placed directly on the glass. Tour replicates of 10 females were used for each treatment. Mortality was recorded at 24,48 , and $72 \mathrm{~h}$. Afterward, survivors of each replicate were moved to an untreated plastic cage (12 cm in diameter, $5 \mathrm{~cm}$ in height) with a hole in the lid $(5 \mathrm{~cm}$ in diameter) covered by a gauze to provide ventilation. Food and water were supplied as described for parasitization cages. Mortality was recorded every day until the last insect died. Then, mean longevity was assessed as the averaged number of days that insects survived for each replicate. No parasitization rate could be recorded.

Cover Spray (Semifield Test). Small olive trees ('Cornicabra') planted in pots ( $50 \mathrm{~cm}$ in diameter, 60 $\mathrm{cm}$ in height) were sprayed with a hand sprayer until the point of runoff. These olive trees are kept on the field at the facilities of Universidad Politécnica de Madrid.

As soon as trees were dried ( $2 \mathrm{~h}$ later), they were covered with a wooden cage designed by González et al. (1998), and 30 females ( $\angle 48 \mathrm{~h}$ old) per tree were released inside. Each cage consisted of a wooden base and a wooden, plastic, and gauze frame. The wooden square bases were $25 \mathrm{~cm}$ in length. In one side was a rectangular hole $(13$ by $2 \mathrm{~cm})$ to fit to the tree's trunk. To prevent insects coming in or out from the cage, Plasticine was used to seal the space between the trunk and the floor. The frames were $60 \mathrm{~cm}$ in height. The top and three of the sides were covered with a mesh, and the fourth side consisted of a methacrylate sheet to easily check the experiment. Water was prom vided as described in the former experiment. Diet was supplied in a V-shaped cardboard. Both water and diet containers were hung with a wire to the branches.

Each tree was considered an experimental unit. Three replicates per insecticide and control (water) were performed. Mortality was recorded at 24,48 , and $72 \mathrm{~h}$. After $3 \mathrm{~d}$, survivors from each replicate were taken to the laboratory to test parasitization rate following the methodology described previously.

Bait Treatment (Extended Laboratory Test). Small branches of olive trees with five to six leaves per branch were collected. Five droplets of $1 \mu$ leach of the corresponding bait treatment were randomly distributed on the upper side of the leaves with a micropipette in the laboratory. Therefore, $5 \mu$ l of the bait treatment in total was applied per branch. Each treated branch was placed in an untreated plastic cage with food and water as described in cover sprays, laboratory test. Ten females per replicate were released and exposed to treated leaves for $3 \mathrm{~d}$. Five replicates of each treatment were performed. Mortality and parasitization rate (attacked host and offspring) were measured as described above.

Bait Treatment (Persistence Test). To test the persistence of the bait-formulated compounds pesticides, droplets of $1 \mu l$ each were applied with of micropipette on the leaves of the small olive trees as described in the former experiment, but in the field. The same olive tree never contained droplets of different compounds. Moreover, to identify correctly the treated leaves, they were marked with different colored ribbons, depending on the compound tested. Persistence test were carried out in fall (12 October-15 November, 2006), and plants were maintained in the field at $11.2 \pm 0.7^{\circ} \mathrm{C}\left(\mathrm{t}_{\text {min }}, 6.5^{\circ} \mathrm{C} ; \mathrm{t}_{\text {max }}, 17.5^{\circ} \mathrm{C}\right)$, and the average rainfall was $0.14 \pm 0.2 \mathrm{~mm}(\mathrm{mix}, 0 \mathrm{~mm} ; \max , 2.2 \mathrm{~mm})$. P. concolor females were exposed in the laboratory to samples of the treated leaves (five treated leaves per cage) taken at different time intervals after pesticide application: $7,14,21$, and $34 \mathrm{~d}$. The untreated plastic cages with food and water as described in the former experiment were used. Five replicates of each treat ment and residue aged, and 10 females per replicate were performed. Only those pesticides classified as not harmless in the previous experiments were chosen to be tested in persistence tests, according to IOBC guidelines. As there were no differences among control (water) and bait, only bait was used in this trial as control. Mortality at days 1 and 3 was recorded for each aged residue. No parasitization rate could be recorded. The experiment finished for any insecticide tested when mortality at day 3 was $<30 \%$ or the aged residue tested was $>30 \mathrm{~d}$

Exposure via Treated Host. Groups of 50 neonate C. capitata larvae were reared in nonventilated rearing cages $(9 \mathrm{~cm}$ in diameter and $2 \mathrm{~cm}$ in height) with $50 \mathrm{~g}$ of artificial diet. When they were $5 \mathrm{~d}$ old, $5 \mathrm{ml}$ of the insecticide solutions was added to the diet with a 
Table 1. Laboratary regidual contact toxicity (mean percentage of camblative mortality) to $P$. concolor femalea when intecticides we applied as cover oprays

\begin{tabular}{|c|c|c|c|c|c|c|}
\hline \multirow{2}{*}{ Compourd } & \multirow{2}{*}{$\begin{array}{c}\text { Concn } \\
\text { (mg [AI }] / \text { liter })\end{array}$} & \multicolumn{3}{|c|}{$\%$ mortality } & \multirow{2}{*}{ Langevity (d) } & \multirow{2}{*}{$\begin{array}{l}10 \mathrm{BO} \\
\text { catego }\end{array}$} \\
\hline & & Day 1 & Day 2 & Day 3 & & \\
\hline Control & & $0,0 \pm 0.0 \mathrm{a}$ & $0.0 \pm 0.0 \mathrm{a}$ & $0.0 \pm 0.0 \mathrm{a}$ & $23.8 \pm 2.7 a$ & \\
\hline Dirnethoate & 600 & $100=0.0 \mathrm{c}$ & $100 \pm 0.0 \mathrm{c}$ & $100 \pm 0.0 \mathrm{c}$ & & 4 \\
\hline Inidacloprid & 150 & $28.3 \pm 7.4 b$ & $65.0 \pm 11.7 \mathrm{~b}$ & $75.0 \pm 9.2 b$ & $2.3 \pm 0.2 b$ & 3 \\
\hline Fipronil & 40 & $100 \pm 0.0 \mathrm{c}$ & $100 \pm 0.0 . c$ & $100 \pm 0.0 \mathrm{c}$ & & 4 \\
\hline F & & 189.67 & 73.29 & 90.44 & 279.64 & \\
\hline త & & 3,12 & 3,12 & 3,12 & 1,6 & \\
\hline$p$ & & $<0,0001$ & $<0,0001$ & $<0,0001$ & $<0.0001$ & \\
\hline
\end{tabular}

Within the same column, data (mean \pm SE) values followed by a different letter are significantly different $(P<0.05 ;$ ANOVA, LSD test)

${ }^{a}$ IOBC toxicity rating for laboratory (inert susbstrate): 1, harchless (<30\%); 2 , slightly harmful (30-79\%); 3 , moderately harnful (80 $-99 \%$ ) 4, harmful ( $>99 \%$ ). Highest value among the two IOBC categories calculated previously (mortality at day 3 , longevity).

pipette and very carefully mixed. Concentrations of fipronil (1 mg [AI]/liter) and imidacloprid (10 $\mathrm{mg}$ [AI] / liter) determined to be sublethal for C. capitata in former experiments carried out in our laboratory (Abdallahi Ould-Abdallahi 2004) were used. After $48 \mathrm{~h}$ in contact with the insecticides, $30 \mathrm{7d}$ d-old (mature third-instar) larvae were randomly chosen and were offered for oviposition to five female wasps per treatment at the rate 6:1 (host/parasitoid), optimal rate of parasitism according to Avilla (1982). The procedure followed to measure the parasitism has been previously described in residual contact experiments, although in this case, C. capitata larvae were only exposed for $\mathrm{l} \mathrm{h}$ to parasitization. Ten replicates of each treatment and control were tested. In addition, 10 replicates of 30 treated larvae of nonparasitized $C$. capitata were followed until adult emergence to test the toxicity of the sublethal concentrations of the insecticides in the host. Emerged flies, attacked hosts, and wasp progeny were evaluated.

Data Processing and Statistical Analysis. Data (mean values and $\mathrm{SE}$ ) were stbjected to onemway analysis of variance (ANOVA), and Fisher's lest significant difference (LSD) test was used to compare the responses to different treatments. Statistical ana!yses were performed using STATGRAPHICS version 5 (Graphic Software System, STSC Inc., Rockville, MD). When necessary, data were transformed to the arcsine $V(x / 100)$, although nontransformed data are shown in the tables. When any of the premises of the ANOVA was violated after these transformations, the nonparametric Kruskal-Wallis test was applied. Median values were considered significantly different if the $95 \%$ confidence intervals of medians did not overlap.

Schneider-Orelli formulae were used to calculate corrected mortality or reduction in any other parameter in comparison with the untreated control. Subsequently, pesticides were classified into the four IOBC toxicity categories (Hassan 1994), once any of the parameter evaluated (mortality at $72 \mathrm{~h}$, longevity, attacked host, and offspring) have been corrected. IOBC categories shown in tables correspond to the worst case, the highest value among the IOBC categories obtained for each parameter within an insecticide. Finally, insecticides were ranked as 1 , harmless
$(<30 \%$ reduction $) ; 2$, slightly harmful $(31-79 \%$ reduc tion); 3 , moderately harmful ( $80-99 \%$ reduction); and 4, harmoful (>99\% reduction) for laboratory test with inert substrate and as 1 , harmless ( $<25 \%$ reduction) 2 , slightly harmful $(25-50 \%$ reduction $) ; 3$, moderately harmful (51-75\% reduction); and 4 , harmful $(>75 \%$ reduction) for laboratory test with vegetable substrate and semifeld tests. For the evaluation of persistence. the following evaluating categories of the IOBC were used (Hassan 1994): A, short lived ( $\angle 5$ d); B, slightly persistent $(5-15 \mathrm{~d}) ; \mathrm{C}$, moderately persistent $(16-30$ d); and D, persistent (>30 d).

\section{Results}

Exposure via Residual Contact (Cover Spray) . All the three insecticides evaluated were harmful for $P$ concolor females after exposure to fresh residues on glass surfaces (Table 1). Fipronil exhibited a direct toxicity similar to dimethoate and caused $100 \%$ mor tality at $24 \mathrm{~h}$. For imidacloprid a delayed effect on mortality was observed in comparison with dime thoate and fipronil, but it increased with time and only a few females survived (25\%) at day 3. This insecticide produced a significant reduction in female longevity compared with the control ( $\approx 90 \%$ ), and at day 5 all the wasps were dead. Consequently, it was not pos. sible to study the parasitization rate.

Under semifield conditions (Table 2), dimethoate and fipronil were very toxic. Both insecticides caused $100 \%$ mortality $3 \mathrm{~d}$ after treatment (IOBC toxicity rating 4). Females exposed to residues on treated trees were more tolerant to imidacloprid. In contrast with the laboratory results ( $75 \%$ mortality at day 3 ), imidackoprid did not produce a significant mortality of the wasps in this treatment (15.6\% mortality at day 3 ), although it did cause some sublethal effects on their reproductive capacity. This insecticide reduced significantly the percentage of attacked hosts by $>25 \%$ compared with the control and also the offspring by $>55 \%$ (IOBC toxicity rating 3 ).

Exposure via Residual Contact (Bait Spray). Imidacloprid applied as bait spray was harmless to $P$. concolor both concentration tested: 150 and $1,500 \mathrm{mg}$ (AI) /liter (Table 3). It produced neither mortality in adults nor a reduction of the parasitization rate com- 
Table 2. Sexulfield resiờal contact toxtcity to P. concolor femoles when inosetioldes were applied cover aprayg

\begin{tabular}{|c|c|c|c|c|c|c|c|}
\hline \multirow{2}{*}{ Compound } & \multirow{2}{*}{$\begin{array}{c}\text { Concn } \\
\{\mathrm{mg}[\mathrm{AI}] / \text { liter }\rangle\end{array}$} & \multicolumn{3}{|c|}{ \% mortality } & \multirow{2}{*}{$\begin{array}{c}\text { \% attacked } \\
\text { host }^{2}\end{array}$} & \multirow{2}{*}{$\begin{array}{c}\% \\
\text { offsprirg }\end{array}$} & \multirow{2}{*}{$\begin{array}{c}\text { IOBC } \\
\text { eategory }\end{array}$} \\
\hline & & Day 1 & Day 2 & Day 3 & & & \\
\hline Control & & $4.4 \pm 4.42$ & $4,4 \pm 4.48$ & $4.4 \pm 4.4 a$ & $53.1 \pm 1.6 \mathrm{a}$ & $74.8 \pm 7.2 \mathrm{a}$ & \\
\hline Dimethoate & 600 & $52.2 \pm 7.36$ & $92.2 \pm 2.9 b$ & $100 \pm 0.0 \mathrm{~b}$ & & & 4 \\
\hline Imidacloprid & 350 & $5.5 \pm 5.5 a$ & $10.0 \pm 3.3 \mathrm{~B}$ & $I 5.6 \pm 8.9 \mathrm{a}$ & $38.1 \pm 2.7 \mathrm{~b}$ & $32.5 \pm 13.1 \mathrm{~b}$ & 3 \\
\hline Fipronil & 40 & $88.9 \pm 6.2 \mathrm{c}$ & $98.9 \pm 1.1 \mathrm{~b}$ & $100 \pm 0.0 b$ & & & 4 \\
\hline$F$ & & 46.68 & 2566.69 & 130.24 & 23.17 & 7.98 & \\
\hline$d f$ & & 3,8 & 3,8 & 3,8 & 1,14 & $1,1,4$ & \\
\hline$P$ & & $<0.0001$ & $<0.0001$ & $<0.0001$ & 0.0003 & 0,0135 & \\
\hline
\end{tabular}

Within the same column, data (mean \pm SE) followed by a different letter are significantly different $(P<0.05$; ANOVA, LSD test).

" Percentage of parasitized pupae from larvae offered.

${ }^{b}$ Percentage of parasitoids emerged from parasitized pupac.

- IOBC categories in semifiejd tests; 1 , harnaless $(\langle 25 \%)$; 2 , slightly harmful (25-50\%); 3 , moderately harmful $(51-75 \%)$; and 4 , harmful (>75\%). Highest value among the three IOBC categories calculated previously (mortality at day $3, \%$ attacked host and progeny size)

pared with the water or bait controls. Fipronil and dimethoate killed $100 \%$ P. concolor females after $72 \mathrm{~h}$ of exposure (KOBC toxicity rating 4 ). Bait alone did not show any toxic effects on the insects.

When the persistence of the pesticides was studied (Table 4), for residues up to $14 \mathrm{~d}$ old, fipronil and dimethoate exhibited similar toxicity and caused high or total mortality, after $3 \mathrm{~d}$ of exposure. On day 21 , dimethoate toxicity was lower than that of fipronil (IOBC toxicity ratings of 3 and 4 , respectively). The largest difference was observed when the wasps were exposed to 34-d-old residues because dimethoate was harmless (IOBC toxicity rating 1 ) and fipronil was still harmful (IOBC toxicity rating 4). The toxicity of fipronil did not decrease with time, irrespective of residue age and mortality at $24 \mathrm{~h}$ was always $>60 \%$. Thus, according with these results, fipronil was classified as persistent (category D) and dimethoate as moderately persistent (category C).

Exposure via Treated Host. Table 5 shows the biological activity of imidacloprid and fipronil in the host-parasitoid complex when fully grown C. capitato larvae reared in treated media were offered to females of $P$. concolor for parasitization.
C. capitata larval development (nonparasitized larvae) was unaffected when they were exposed to sublethal concentrations of fipronil and imidacloprid, and the percentages of adult flies under these treatments conditions were similar to those of controls. However, negative effects were observed in the parasitoid progeny when they developed inside treated C. capitata larvae. Fipronil completely inhibited $P$. concolor emergence. Imidacloprid had lower negative effects although there was a significant reduction in the offspring compared with the control (33.8\%). Therefore, the product was classified as shightly harmful (IOBC toxicity rating 2 ).

\section{Diseussion}

In our assays, we found that fipronil and imidacloprid were toxic to $P$. concolor, but to different degrees. Fipronil severely affected the survival of females and larvae (via treated host) of $P$. concolor, irrespective of the route of contamination, whereas the effects of imidacloprid were lower than that of the standard dimethoate.

Table 3. Residuml eortast toxicity to $P$. concolor females when the insecticides were applied as haited aprays to olive plants

\begin{tabular}{|c|c|c|c|c|c|c|c|}
\hline \multirow{2}{*}{ Compound } & \multirow{2}{*}{$\begin{array}{c}\text { Concn } \\
\text { (mg [AI]/liter) }\end{array}$} & \multicolumn{3}{|c|}{ \% mortality } & \multirow{2}{*}{$\begin{array}{c}\text { \% attrokeda } \\
\text { hosts }\end{array}$} & \multirow{2}{*}{$\%$ offspring } & \multirow{2}{*}{$\begin{array}{c}\text { IOBC } \\
\text { category }\end{array}$} \\
\hline & & Day 1 & Day 2 & Day 3 & & & \\
\hline Control & & $2.0 \pm 2.0 \mathrm{a}$ & $2.0 \pm 2.0 \mathrm{a}$ & $4.0 \pm 2.5 a b$ & $81.5 \pm 3.2 a$ & $75.5 \pm 6.1 \mathrm{a}$ & \\
\hline Bait & 4,500 & $0.0 \pm 0.0 \mathrm{a}$ & $2.0 \pm 2,0 a$ & $2.0 \pm 2.0 \mathrm{a}$ & $68.5 \pm 5.4 a$ & $73.8 \pm 6.2 a$ & 1 \\
\hline Bimethoate + bait & $3,000+2,250$ & $52,0 \pm 19.9 \mathrm{~b}$ & $96.0 \pm 4.0 \mathrm{c}$ & $100 \pm 0.0 \mathrm{c}$ & & & 4 \\
\hline Imidacloprid + bait & $150+2,250$ & $2.0 \pm 2,0 \mathrm{a}$ & $6.0 \pm 4.0 \mathrm{a}$ & $8.0 \pm 3.7 b$ & $74.0 \pm 5.0 \mathrm{a}$ & $77.1 \pm 4.5 \mathrm{a}$ & 1 \\
\hline Inidacloprid + bait & $1,500+2,250$ & $0.0 \pm 0.0 \mathrm{a}$ & $0.0 \pm 0.0 \mathrm{a}$ & $0.0 \pm 0.0 \mathrm{a}$ & $72.4 \pm 5.4 \mathrm{a}$ & $74.6 \pm 5.5 \mathrm{a}$ & $\mathbf{I}$ \\
\hline Eipronil + bait & $40+2,250$ & $16.0 \pm 6.8 \mathrm{a}$ & $86.0 \div 5.1 b$ & $100 \pm 0.00$ & & & 4 \\
\hline$F$ & & $15.5063^{d}$ & 191.13 & 622.57 & 1.27 & 0.16 & \\
\hline$d f$ & & & 5,24 & $5,2 A$ & 3,36 & 3,36 & \\
\hline$p$ & & 0.0084 & $<0.0001$ & $<0,0001$ & 0.298 & 0.923 & \\
\hline
\end{tabular}

Five droplets ( $\mu$ l each) per replicate. Within the same column, data (mean \pm SE) followed by a different letter are significantly different $(P<0.05$, ANOVA or Kruskal-Wallis, LSD test $)$.

a percentage of parasitized pupae from larvae offered.

Percentage of parasitoids emerged from parasitized pupae.

'IOBC categories in laboratory extended assay (vegetable substrate): 1 , harmless $(<25 \%) ; 2$, slightly harmuful $(25-50 \%) ; 3$, moderately harmful $(51-75 \%)$; and 4 , harnful (>75\%). Highest value among the three IOBC categories calculated previously (mortality at day 3 , \% attacked host and progeny size).

Hruskal-Wallis test. 
Table 4. Persibsence of harmful imsecticides to $P$. concolor females using haited inbeticides applied on alive leaves

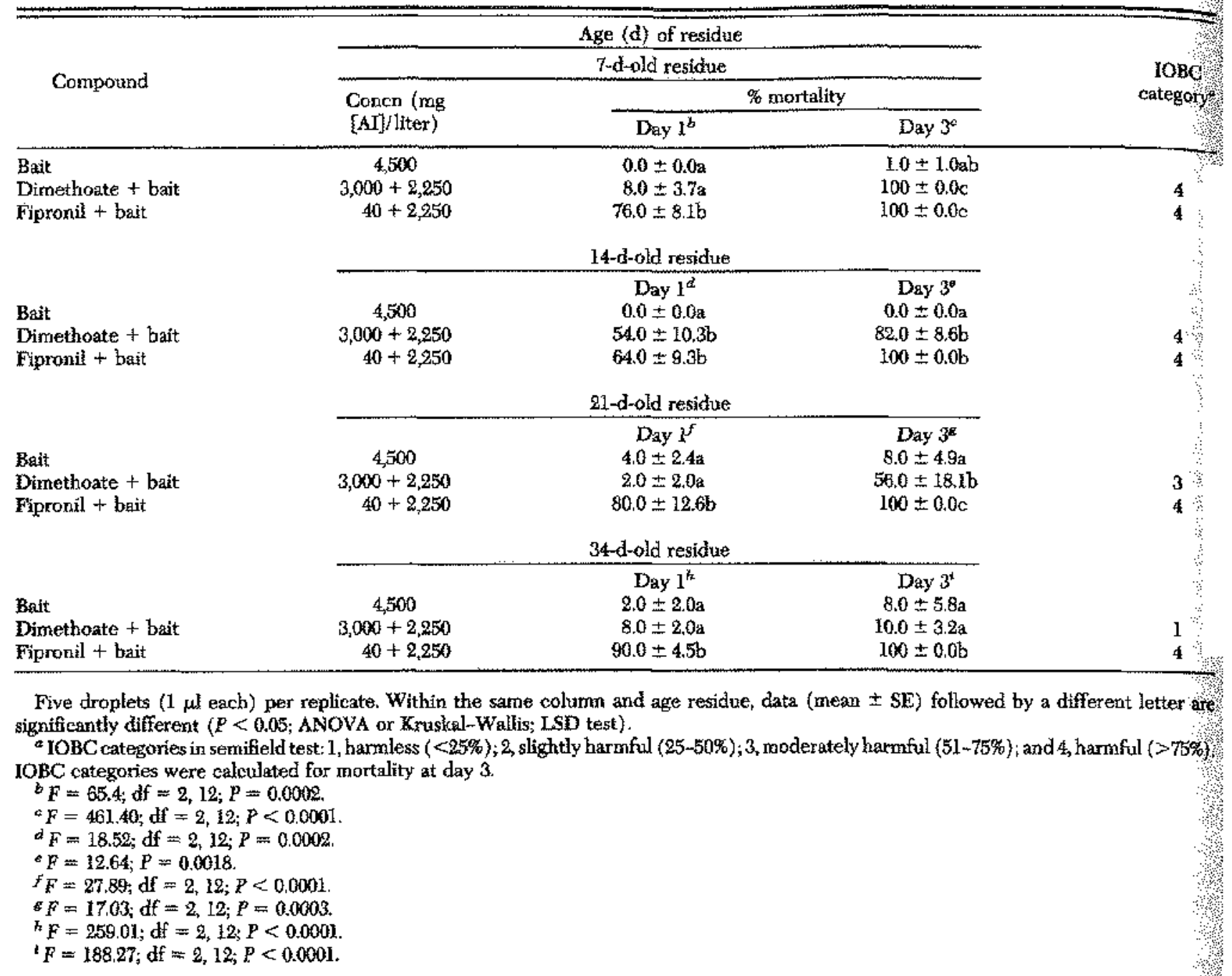

Dimethoate has been used since 1956 on cultures of fruits, vegetables, grain ${ }_{s}$ and fodder (Brunet et al. 1997). In Spain, it is the insecticide more used against olive fruit fly (Ruiz et al. 2004). The potential danger of dimethoate to nontarget species has been reported in fishes, birds, and mammals (Brunet et al. 1997) as well as soil-dwelling beetles (Gyldenkaerne et al. 2000 ) and natural enemies such as the predacious mite Eusieus tularensis Congdon and the parasitic wasp Aphytis melinus DeBach (Phillips et al. 1987).
Ruiz Torres and Montiel Bueno (2002) studied the effect of dimethoate on insect communities for $3 \mathrm{yr}$, on eight different located olive tree canopies (in Jack Spain). The insecticide was applied with terrestrial cover sprays against $B$. oleae and Prays oleae (Bernard) and aerial bait sprays to control $B$. oleae. Dimethoate reduced the abundance and diversity of entomological olive fauna by using both sprays but the terrestrial cover sprays had more impact than the aerial bait sprays.

Tabse 5. Toxieity of pesticides via the food chain: inffuence on host and parasitoid eraergence

\begin{tabular}{|c|c|c|c|c|c|}
\hline Compound & $\begin{array}{c}\text { Conen } \\
\text { (mg [Al]/iter }\end{array}$ & $\begin{array}{c}\text { \%C. capitato adult } \\
\text { mergence }\end{array}$ & $\begin{array}{l}\text { 算 attacked } \\
\text { hosts } s^{b}\end{array}$ & $\begin{array}{c}\% \\
\text { offspring }\end{array}$ & $\begin{array}{l}\text { IOBC } \\
\text { category }\end{array}$ \\
\hline Control & & $88.0 \pm 2.8 \mathrm{a}$ & $85.7 \pm 3.2 \mathrm{a}$ & $78.3 \pm 4.2 a$ & \\
\hline Imidacloprid & 10 & $95.3 \pm 1.9 \mathrm{a}$ & $96.4 \pm 1.7 \mathrm{~b}$ & $51.8 \pm 3.0 b$ & 2 \\
\hline Fipronil & 1 & $93.0 \pm 2.6 \mathrm{a}$ & $83.0 \pm 3.5 \mathrm{a}$ & $0 \mathrm{c}$ & 4 \\
\hline$F$ & & 2.27 & 5.94 & 178.00 & \\
\hline df & & 2,27 & 2,27 & 2,27 & \\
\hline$P$ & & 0.122 & 0.007 & $<0.0001$ & \\
\hline
\end{tabular}

Within the same column, data (mean $4 \mathrm{SE}$ ) followed by a different letter are significantly different $(P<0.05$; ANOVA, LSD test).

${ }^{a}$ From nonparasitized larvae.

${ }^{b}$ Percentage of parasitized pupae from larvae offered.

${ }^{c}$ Percentage of parasitoids emerged from parasitized pupae.

¿ IOBC categories in laboratory test: 1 , harnless $(<30 \%) ; 2$, sligbtly harmful $(30-79 \%) ; 3$, moderately hannful $(80-99 \%) ; 4$, barmful $(>99 \%)$, 
Many studies have shown a negative impact on natiral enemies when cover sprays of fipronil are applied. Balanca and Visscher (1997) observed a negative effect on several families of Coleoptera and Hymenoptera in the field. In laboratory assays, Elzen et all (2000) and Medina et al. (2004) also observed that fopronil killed all the exposed adults of the parasitoid Catolaccus grandis (Burks) (Hymenoptera: Pteromalin dae) and all the larvae of the predator Chrysoperla camea (Stephens) (Neuroptera: Chrysopidae) in con. tact with to residues of the insecticide.

When we carried out the laboratory contact exper inent using cover spray, the effects of imidacloprid on females were not particularly strong after $l \mathrm{~d}$ of contact $(\angle 50 \%)$, so the high mortality recorded in the following days was probably caused by repeated contact with the toxins through tarsal contact due to walking in a limited space and by ingestion of the diet placed on the treated surface, which is expected to be contaminated. Lowery and Smirle (2003) observed that imidacloprid was more toxic when the route of uptake was ingestion compared with contact. This nay be the reason explaining the lower damage to females of $P$. concolor in comparison with fipronil and dimethoate, when the main mode of exposure was contact.

In the semifield assay, cover sprays of imidacloprid eaused no mortality due to contact with the treated trees. The different toxicity observed for imidacloprid in the cover spray assays on an inert substrate (glass plate), in the laboratory, compared with the semifield experiments, using a plant substrate, might be explained only in part, due to the absorption of the insecticide into olive leaves during the three days of exposure. Wise et al. (2007) recorded presence of imidacloprid residues in surface and subsurface of blueberry (Vaccinium spp.) leaves and fruit, after a cover spray at different times. Although residues of imidacloprid were predominantly in the surface $4 \mathrm{~h}$ after the application, a little proportion of insecticide had been moved to the subsurface at this time. A large portion of the imidacloprid residue moved to subsurface of fruit and leaf tissue within $7 \mathrm{~d}$. Obviously, there were larger area for finding refuges in the semifield test than in the laboratory test and, in consequence, it was easier for the parasitoids avoiding the contact with the insecticide, which it can be applied to all the insecticides tested. Therefore, the physiological selectivity of imidacloprid to $P$. concolor seems to be higher compared with that of fipronil or dimethoate, although still very toxic in the semifield test.

However, imidacloprid survivors in the semifeld test caused a significant reduction in both parasitization parameters evaluated: percentage of attacked host and offspring. Similar sublethal effects such as the reduction of host foraging ability and fecundity of predators and parasitoids as a result of contact with the insecticide also has been observed (Gentz et al. 2010). These effects were studied in Microplitis croceipes Gresson when exposed to treated cotton, Gossypium hirsutum L., plants (Stapel et al. 2000) or in Anagyrus pseudococci (Girault) after feeding on nectar from buckwheat, Fagopurum esculentum Moench, flowers treated with label-rate soil applications (Krischik et al. 2007). Furthermore, contact with imidacloprid doubled the amount of time needed to produce the first egg in the predator Coleomegilla maculate Timberlake (Smith and Krischik 1999).

Imidacloprid, when applied in a bait treatment at the very high concentration of $1,500 \mathrm{mg}$ (AI)/liter, was harmless to the parasitoid. In contrast, fipronil, used at a concentration 37.5 times lower, had a very negative impact on $P$. concolor, similar to dimethoate. To ow knowledge, there is no information available about the toxicity of fipronil bait spray for other species of natural enemies.

Protein bait application techniques have been shown to be less harmful to beneficial insects, because the surface exposed is much smaller than those when cover sprays are applied (Roessler 1989, Ruiz et al. 2002, Urbaneja et al. 2009); therefore, the higher the possibility of avoiding the contact with the insecticide, unless the bait was very attractive to the parasitoid. In our assays, Psyttalia fernales were observed feeding on honey but not on bait insecticide. Wang et al. (2005) observed similar results in Fopius arisanus (Sonan) (Hymenoptera: Braconidae) by using a treatment of spinosad mixed with GF-120 Fruit Fly Bait (Dow AgroSciences LLLC, Indianapolis, IN).

Toxicity of bait sprays in natural enemies has been less studied compared with cover sprays. Research carried out with similar methodology to that used in this work showed that toxicity depends on the insecticide as well as the evaluated species. Urbaneja ef al. (2009) shown that spinosad (the bait formulation Spintor Cebo) was the most selective compound to Cryptolaemus montrouzieri Mulsant and Neosiulus californicus McGregor. However, phosmet and lambdacyhalothrin, using as bait sprays, were selective to Aphidius colemani Viereck, whereas spinosad (Spintor Cebo) was toxic. However, malathion, an organophosphate with a high contact activity, was toxic for the three species (Urbaneja et al. 2009). Medina et al. (2004) found that $C$. montrouzieri and Rodolia cardinalis (Mulsant) were unaffected by spinosad bait formulated when exposed to 5 droplets of $1 \mu$ l each but killed by malathion.

In contrast to imidacloprid, fipronil applied as bait spray had harmful, long-lasting effects on $P$. concolor. The persistence of this insecticide may be due in part to the combined action of the parent compound and several metabolites produced in its natural degradation, such as the more persistent and less selective sulfone metabolite and desulfinyl photoproduct (Hainzl et al. 1998, Chauzat et al. 2006).

The negative long-term effects of fipronil also have been detected using cover sprays by other researchers. In accord with our results, in a field experiment targeted at Schistocerca gregcria (Forskal), Balanca and Visscher (1997) observed very poor recolonization of species in the hymenopteran families Scelionidae and Sphecidae $4 \mathrm{wk}$ after fipronil treatment, causing almost $100 \%$ mortality in both groups. Similarly, fipronil exhibited high residual activity in adults of 
Anaphes tole Girault (Hymenoptera: Mymaridae) when they were exposed to 30-d-old residues on vegetable surfaces (Williams et al, 2003).

Both fipronil and imidacloprid reduced the percentage of parasitoid's offspring after being developed in a host treated with sublethal concentrations of the pesticides. Although the rate of fly emergence from nonparasitized larvae was not reduced, fipronil treatment did not allow any parasitoid development to the adult stage, whereas imidacloprid treatment resulted in the emergence of only half the number of progeny,

González and Viñuela (1997) also observed a higher susceptibility to pesticides in this parasitoid compared with their host when $C$. capitata larvae were treated with azadirachtin and tebufenozide. This higher susceptibility could be based on the age and time of exposure, because although $C$. capitata third instars were fed on a contaminated diet for only $2 \mathrm{~d}$, the parasitoid had fed on contaminated host tissues since the first instar.

It is generaliy considered that endoparasitoid larvae, inside their host, are more protected from pesticides than flying adults, which can be easily contaminated by contacting residues on plants. However, at the sublethal concentration of $10 \mathrm{mg}$ (AI) / liter, imidacloprid applied via treated host was more toxic to the parasitoid than when females were exposed to cover sprays residues under semifield conditions ( 150 $\mathrm{mg}[\mathrm{AI}] /$ liter) or to bait treatment residues in the laboratory (1,500 $\mathrm{mg}[\mathrm{All} /$ /liter).

In conclusion, our results suggest that the differential mortality of $P$. concolor parasitoids observed in this study due to different routes of exposure to fipronil should be considered when using this insecticide in field treatments. Although imidacloprid is physiolog ically active against females of $P$. concolor, ecological selectivity may result through the use of bait treatment. However, cover sprays with this insecticide should be fully tested in the field to understand their impact on parasitoid development and on the reprom ductive capacity of the females.

\section{Acknowledgments}

This research was partially funded by the Ministry of Science and Innovation (AGL2007-66160-C03-02) to Pilar Medina

\section{References Cited}

Abdallahi Ould-Abdaliahi, E. A. 2004. Evaluación de mordernos plaguicidas en el complejo Ceratitis capitoto (Wiedemann) (Diptera: Tephritidae). Tesis Doctoral. Universidad Politécnica de Madrid, Madrid, España.

Allsood, A. J.y E. T. Vueti, C. L. Leblancy and R. Bull. 2002. Eradication of introduced Bactrocera species (Diptera Tephritidae) in Nauru using male annihilation and pro. tein bait application techniques, pp. $19+25$. In C. R. Veitch and M.N.J. Clout (eds.), Turning the tide: the eradication of invasive species. Proceedings, the International Conference on Eradication of Island Invasives. IUCN Publications Services Unit, Cambridge, United Kingdom.
Avilla, 3. 1982. Estudio de la proporción de sexos en pobla ciones de laboratorio del parasitoide Opits concelor (Szepl.) (Hymenoptera: Braconidae) criado sobre $C_{t}$ atitis capitata Wied. (Diptera: Trypetidae). Tesis Doco toral. Universidad Politécnica de Madrid, Madrid, España

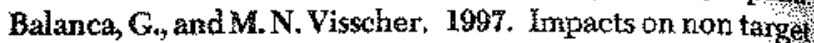
insects of a new insecticide compound used against the desert locust (Schistocerca gregaria). Arch. Envison. Con. tamin. Toxicol. 32; $58-62$.

Barry, J. D., S. Polavarapu, and L.A.F. Teixeira, 2004, Eval vation of traps and toxicants in an attract-and-kill systen for Rhagoletis mendax (Diptera: Tephritidae). J. Econ Entomol. 97; 2006-2014.

Brunet, R, C. Girard, and A. Cyr. 1997. Comparative stud, of the signs of intoxication and changes in activity level of red-winged blackbirds (Agelaius phoeniceus) exposed to dimethoate. Agric. Ecosyst. Environ. 64: 202-209.

Burris, E., B. R. Leonard, S. H. Martin, C. A. White, and J. B. Graves. 1994. Fipronil: evaluation of soil and folfar treats ments for control of thrips, aphids, plant bugs and boll weevils, pp. $838-844$. In Proceedings, the Beltwide $\mathrm{Col}$ ton Conference. National Cotton Council, Memphis, TN

Chauzat, M. P, J. P. Faucon, A. C. Martel, J. Lachaize, N Cougoule, and M. Aubert. 2006. A survey of pesticide residues in pollen loads collected by honey bees in France. J. Econ. Entomol, 99: 253-262.

Cole, L. M., R. A. Nichalson, and J. E. Casida. 1993. Action of phenylpyrazole insecticides at the GABA-gated chlo ride channel. Pestic. Biochem. Physiol 46: 47-54.

Elbert, A., B. Becker, I. Hartwig, and C. Erdelen. 1991 Imidacloprid a new systemic insecticide. Planzenschultz-Nachr. Bayer 44: I13-136.

Elzen, G. W., S. N.Maldonado, and M. G. Rojas, 2000. Lethal and sublethal effects of selected insecticides and an insect growth regulator on the Boll Weevil (Coleoptera: Curt culionidae) ectoparasitoid Catolaccts grandis (Hyme noptera Pteromalidae). J. Econ. Entomol. 93: 300-303.

Gentz, M. C., G. Murdoch, and G. F. King, zol0. Tandem use of selective insecticides and natural enemies for ef fective, reduced-risk pest managenent. Biol, Control 52 : $208-215$.

Conzález, M., and E. Viñuela. 1997. Effects of two modern pesticides: azadirachtin and tebufenozide on the parasi toid Opius concolor Szèpligeti. IOBC/WPRS Bull, 20:223 240.

Gonzallez, M. F. Bahena, and E. Vinuela. 1998. Desarrollo de un método de semicampo para el estudio de los efectos secundarios de los productos fitosanitarios sobre el parasitoide Opius concolor Szépligeti. Bol. San. Veg, Plagas 24; $661-668$.

Gyldenkaerne, S, H. P. Ravn, and B. Halling-Sorensen. 2000. The effect of dimethoate and cypermethrin on soll-dwelling beetles under semi-field conditions. Chemosphere 41 : $1045-1057$.

Hassan, S. A. 1984. Activities of the TOBC/WPRS working group pesticides and beneficial organisms. IOBC/WPAS Bull. 17: 1-5.

Hainzl, D., L. M. Cole, and J. E. Casidan 1998. Mechanisms for selective toxicity of fipronil insecticide and its sulfone metabolite and desulfinyl photoproduct. Chem. Res. Toxicol. 11; 1589-1535.

Jacas, I., and E. Viñuela. 1904. Analysis of a laboratory method to test the effects of pesticides on adult females of Opitus concolor, a parasitoid of the olive fruit fly. Biocontrol Sci. Technol, 4: 147-154.

Jiménez, A. T. Castillo, and P. Lorite. 1990. Supervivencia del himenoptero bracónido Opits concolor Szèpl parasito 
de Dacus oleae Gmelin en olivares de Jaén. Bol. San. Veg. Plagas 16: 97-103.

Krischik, V. A. A. L. Landmark, and G. E. Heimpel. 2007 . Soil-applied imidacloprid is translocated to nectar and kills nectar-feeding Anagyrus pseudococci (Girault) (Hy. menoptera: Encyrtidae). Environ. Entomol. 36; $1238-$ 1245.

Laropoulos, C., V. G. Mavraganis, T. Broumas, and N. Ragoussis. 2005. Field test on the combination of mass trapping with the release parasite Opius concolor ( $\mathrm{Hy}$ menoptera: Braconidae), for the control of the olive fruit Ay Bactrocera oleae (Diptera: Tephritidae). Integrated Protection of Olive Crops. 1OBC/wprs Bull. 28: 77-81.

Lowery, D. T., and M. J. Smirle. 2003. Comparison of bioassay techniques for determining baseline susceptibilities to imidacloprid for green apple aphid (Homoptera: Aphididae). J. Econ. Entornol. 96: 1864-1871.

[MARM] Ministerio de Medio Ambiente y Medio Rural y Marino. 2011. Mizisterio de Medio Ambiente y Medio Rural y Marino. (www. mapa.es, zuxlx).

Mazor, M. 2009. Competitiveness of fertilizers with proteinaceous baits applied in Mediterranean fruit fly, Ceratitits capitata Wied, (Diptera: Tephritidae) control Crop Prot. 28: $314-318$.

Medina, P., F. Budia, P. Del Estal, A. Adatn, and E. Viñuela 2004. Toxicity of fipronil to the predatory lacewing Chrysoperla carnea (Neuroptera: Chrysopidae). Biocontrol Sci. Technol. 4 : 261-268.

Phillips, P. A., D. Machlitt, and M. Mead. 1987. Non-target effects of dimethoate and acephate against Eusieus tularensis Congdon and Aphytis melinus DeBach on lemons in Califoraia. Crop Prot, 6: 388-392.

hagusa, S. 1974. Influence of temperature on oviposition rate and longevity of $O$. concolor sicultus. Entomophaga 19: $61-66$.

Roessler, Y, I989. Insecticidal bait and cover sprays, pp. 329-335. In A. S. Robinson and G. Hopper (eds.), Fruit flies, their biology, natural enemies and control. Elsevier, Amsterdam, The Netherlands.

Riuiz Torres, M., and A. Montiel Bueno. 2002. Efectos del dimetoato usado en aplicaciones terrestres y aéreas sobre la entomofauna de olivar en la provincia de Jaén. Bol San. Veg. Plagas 28: 525-560.

Ruiz Torres, M., and A. Montiel Bueno. 2007. Eficacia de los tratamientos mediante árboles cebo contra la Mosca del Olivo (Bactrocera oleae, Gmel; Tephritidae, Diptera) en la provincia de Jaén. Bol. San. Veg. Plagas 33: 249-265.

Fuiz Torres, M., C. Madueño, and A. Montiel Bueno. 2004. Ffectividad de tratamientos cebo terrestres con Spinosad e Irnidacloprid contra la Mosca del Olivo (Bactrocera oleae, Gmel, Diptera: Tephritidae). Resultados prelininares. Bol. San. Veg. Plagas 30: 415-425.

Sime, K. R., K. M. Daane, R. H. Messing, and M. W. Johnson. 2006. Conparison of two laboratory cultures of Psyttalia concolor, as a parasitoid of the olive frait fly. Biol. Control 39: $248-255$.
Smith, S. F, and V. A. Krischik, 1999. Effects os systemic imidacloprid on Coelomegilla maculata (Coleoptera Coccinelidae). Environ. Entomol. 28: 1189-1195.

Stapel, J. O., A. M. Cortesero, and W. J. Lewis. 2000. Disruptive sublethal effects of insecticides on biological control: altered foraging ability and life span of a parasitoid after feeding on extrafloral nectar of cotton treated with systernic insecticides. Biol. Control 17: 243-249.

Stark, J. D., and R. I. Vargas. 2005. Toxicity and hazard assessment of fipronil to Daphaia pulex. Ecotoxicol. Environ. Saf. 62: 11-16.

Stark, $\mathbb{J}_{+} \mathrm{D}$, and R. Vargas. 2009. An evaluation of alternative insecucides to diazinon for control of tephritid frutt flies (Diptera: Tephritidae) in sol. J. Econ. Entomol. 102: $139-143$.

Urbaneja, A., P. Chueca, F. Montón, S. Pascual-huiz, O. Dembilio, P. Vanaclocha, R. Abad-Moyano, T. Pina, and P. Castanera 2009. Chemical alternatives to Malathion for controlling Ceratitis capitata (Diptera: Tephritidae). and their side effects on natural eneries in Spanish citrus orchards. J. Econ. Entomol 102: 144-151.

Vargas, R. L, J. D. Stark, B. Mackey, and B. Bull. 2005. Weathering trials of amulet cuemure and annulet methyl eugenol "attract-and kill" stations with male melon flies and oriental fruit flies (Diptera: Tephritidae) in Hawai: J. Econ. Entomol. 98: 1551-1559.

Vargas, R. I., R.F.L. Mau, J. D. Stark, J. C. Pinero, L. Leblanc, and $\mathrm{S}$. K. Souder. 2010. Evaluation of methyl eugenol and cue-lure traps with solid lure and insecticide dispensers for fruit fly monitoring and male annihilation in the Hawaì areawide pest management program. J. Econ. Entomol. 103: 409-415.

Wang, X., E. A. Jarjees, B. K. MeGraw, A. H. Bokonon-Ganta, R. H. Messing, and M. W. Johnson. 2005. Effects of spinosad-based fruit fly bait GF 120 on tephritid fruit fly and aphid parasitoids. Biol. Control 35: 155-162.

Wang, X., M. W. Johnson, K. M. Daane, and Y. Y. Yokoyama. 2009. Larger olive fruit size reduce the efficiency of $P_{\text {syt }}$ talia concolor, as a parasitoid of the olive fruit fly. Biol. Control 49: 45-51.

Williams, L, II, L. D. Price, and V. Manrique 2003. Toxicity of field-weatbered insecticide residues to Anaphes iole (Kymenoptera: Mymaridae), and egg parasitoid cotton. Biol. Control 26: 217-223.

Wise, J. Cn, C. Vandervoort, and R. Isaacs. 2007. Lethal and sublethal activities of Imidacloprid contribute to control of adult Japanese beetle in blueberries. J. Econ. Entomol. 100: $1596-1603$.

Yee, W. L, and D. G. Alston. 2006. Effects of spinosad, spinosad bait, and chloronicotinyl insecticides on mortality and control of adult and larval western cherry fruit fly (Diptera: Tephritidae). J. Econ. Entomol. 99: 1720 1732 . 